\section{Determinants of household income of micro-finance women participants: a quantile regression approach}

Determinants of household income

\author{
Jarita Duasa
}

Department of Economics, Kulliyyah of Economic and Management Sciences, International Islamic University Malaysia, Kuala Lumpur, Malaysia, and

Nur Hidayah Zainal

Academy of Contemporary Islamic Studies, UiTM Kampus Puncak Alam,

Shah Alam, Malaysia

\begin{abstract}
Purpose - The purpose of this study is to adopt quantile regression to investigate the impact of several factors on per capita income of participants of micro-financing scheme (Amanah Ikhtiar Malaysia [AIM]), who are mostly women at different point on the income distributions.

Design/methodology/approach - This study uses data collected from a survey on respondents who are the participants of AIM program using convenience sampling in Perak and Kelantan.

Findings - The empirical results show that the value of asset, value of loan, household size, ratio of spending to income and dummy state are consistently giving similar impacts on per capita income of participants at different quantiles.

Originality/value - However, age negatively and significantly affects per capita income only at middle and lower quantiles but not at higher quantile of per capita income.
\end{abstract}

Keywords Microfinance, Women, Quantile regression, Amanah Ikhtiar Malaysia

Paper type Research paper

\section{Introduction}

There is a growing acknowledgement that microfinance programs have the potential to help the poor, especially women, to develop income-generating activities. The value of microfinance lies in its ability to give credit to normally poor women, whose lack of collateral forces them to rely on expensive informal credit. The cheaper credit is expected to become capital for starting up micro or small businesses that generate income for women, and subsequently increase the welfare of their household members (Pitt and Khandker, 1998). Among the developing countries, Malaysia has a success story and a commendable record in reducing the poverty level in the country. In 1999,

(C) Jarita Duasa and Nur Hidayah Zainal. Published in Ecofeminism and Climate Change. Published by Emerald Publishing Limited. This article is published under the Creative Commons Attribution (CC BY 4.0) licence. Anyone may reproduce, distribute, translate and create derivative works of this article (for both commercial and non-commercial purposes), subject to full attribution to the original publication and authors. The full terms of this licence may be seen at http://creativecommons.org/ licences/by/4.0/legalcode

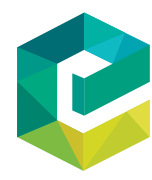

Ecofeminism and Climate Change Vol. 1 No. 1, 2020

pp. $63-7$

merald Publishing Limited p-ISSN: 2633-4062 e-ISSN: 2633-4070 DOI 10.1108/EFCC-03-2020-0002 
EFCC 1,1

it was reported that $8.5 \%$ of the population was under the poverty line. However, after only five years, i.e. in 2004, Malaysia managed to reduce the population living below the poverty level to only $5.7 \%$. Microfinance is one of the objectives of New Economic Policy, which was launched by the Malaysian Government to reduce poverty and income disparities in Malaysia.

The present study looks at the impact of several factors on per capita income of participants of micro-financing scheme (Amanah Ikhtiar Malaysia, AIM) at different point on the income distributions. To the best of our knowledge, studies which analyze the determinants of income generating from microfinance using quantile regression have been non-existent in Malaysia. The structure of this paper is as follows. Section 2 presents an overview of microfinance in Malaysia and literature review on microfinance. Section 3 explains the data and methodology used in the study. Section 4 presents the findings of the study, and finally, Section 5 concludes the study with policy recommendations.

\section{Microfinance in Malaysia and literature review}

Microcredit program in Malaysia started in 1987 with the establishment of AIM. AIM was established to replicate the Grameen Bank model for rural micro-financing (Conroy, 2002). The objective of AIM is to help alleviate rural poverty through provision of micro-financing to the rural poor as a way to generate income. Currently, almost $99 \%$ of the members are women and the loans available are generally on shortterm basis (between 25 and 150 weeks payback time). Beside AIM, public institutions such as agricultural bank (formerly Bank Pertanian, recently has changed its name to Agrobank), as well as the Credit Guarantee Corporation (CGC) also provide lending to small and medium-sized enterprises. However, the loan sizes of these institutions are somewhat above the conventional microfinance.

Initially the banking sector in Malaysia does not put much interest on microfinance. According to McGuire et al. (1998), the central bank of Malaysia, Bank Negara Malaysia, restricted the spread between base and maximum lending rates in the commercial banking system to $4 \%$, and less than that would be required to cover the extra costs associated with microfinance lending. In the case of some loans guaranteed by CGC, the permissible spread was only $2 \%$, reinforcing this effect. Therefore, getting involved in microfinance activity is difficult for commercial bank as well as other institutions. However, AIM, as a government link institution has been successful to help government in alleviating poverty in Malaysia. Grant from the Malaysian Government is one of the success factors that make AIM successful in assisting poor people in Malaysia. As of February 2011, AIM had 264,333 members and had disbursed a total of RM 5.01bn loans (http://www.aim.gov.my). AIM's activities have been directed almost entirely, but not exclusively to the alleviation of poverty among poor Malays.

All impact studies conducted on AIM in 1989 (Amanah Ikhtiar Malaysia AIM, 2008), 1990-1991 (Social and Economic Research Unit [SERU]), 1991-1993 and 19941995 (Amanah Ikhtiar Malaysia AIM, 2008) show that borrowers were able to increase their income after receiving loans from AIM. The impact study conducted by AIM in 2005 shows that borrowers would be out of poverty after four loan cycles with average loan of RM 3,500 per loan. The study also reports that $31 \%$ of borrowers hire family members as workers and another $31 \%$ of borrowers hire non-family members as workers. Therefore, we can conclude that microcredit is a powerful tool to alleviate poverty and generate employment. 
Available empirical studies on the impact of microfinance programs on the poor, especially women, have given mixed results. While some research reports positive results (Hashemi et al., 1996; Pitt and Khandker, 1998), other studies found shortcomings of microfinance programs (Mayoux, 2001; Park and Ren, 2001; Rahman, 1999). Della-Giusta and Phillips (2006) conducted a study highlighting the differences between rural and urban women entrepreneurs in Gambia. Of the two sample groups, given their similar preentrepreneurial experiences, the urban women were found to be more entrepreneurial than rural women. This was probably because of their greater exposure (through tourism), their different educational backgrounds and the larger market place giving more opportunities for trading and learning.

A study undertaken by Mayoux (2001) on microfinance in Cameroon found large disparities in the success and sustainability of women enterprises financed by microcredit. According to Mayoux (2001), rather than class background, the differences seem to come from the women's ability to mobilize and activate social networks. Another study carried out by Mummidi (2009) found controversial results both supporting and denying the assumption that microfinance can promote income generating activities. Mummidi (2009) suggests that a better understanding of the diversity of women's livelihood and a better understanding of the range of constraints, motivations, skills and capabilities of women through the livelihood background might be useful to comprehend the impact of microfinance.

As the microcredit program is aimed to fight the problem of poverty in underdeveloped and developing countries, some literatures are looking at the end results of the program by analyzing the impact of it in reducing poverty level. Chowdhury et al. (2005) pointed out two main findings from their study on Bangladesh. First, microcredit is associated with both lower objective and subjective poverty, and second, the impact of microcredit on poverty is particularly strong for about six years with some leveling off after that point. Another study on Bangladesh conducted by Amin et al. (2003) found that while microcredit is successful in reaching out the poor, it is less successful in reaching out the vulnerable. These results also suggest that microcredit is unsuccessful in reaching out the group most prone to destitution, the vulnerable poor.

Coleman (2006) conducted a study to investigate the impact of group lending program in Northeast Thailand, addressing the issue of self-selection and endogenous program placement, thus leading to biased estimation of impact in previous microfinance impact assessment studies. To overcome this problem, this study conducted quasi experimental impact study and collected detail data on household and village characteristics. The data were analyzed by using Tobit regression and the results show that the impact of group lending is insignificant on physical assets, savings, production, sales, productive expenses, labor time and on most measures of expenditure on health care and education.

Kabeer and Noponen (2005) studied the social and economic impact of PRADAN, a self-help group (SHG) microfinance in Jarkhand, one of the poorest states in India. This study used interview as the tool for qualitative research and use descriptive statistics as the tool for quantitative research. The result of the study shows that PRADAN's SHG-bank linkage model has had significant and positive impact in improving livelihood base, savings and debt position, and living and consumptions standards of participants. PRADAN participants have been able to secure their primary livelihood source through own agriculture supplemented by labor, livestock and non-farm enterprise activities in comparison to more marginally positioned nonmembers who must still rely on unskilled labor activities as their primary source of 
EFCC 1,1

income. The access to financial services and the strengthening of participant's agricultural activities is associated with less vulnerability in terms of higher savings, less onerous debt and less crises related borrowing and more investment in productive activities and fewer months of seasonal migration. It is also associated with significant household welfare gains especially shelter, food security and education. Despite the positive results, this study also showed that empowerment is not an automatic outcome of targeting women for financial services. While gains in terms of women's knowledge, awareness and skills were clearly discernible, impact in terms of participation in decision-making within the home and in the public domain were far more modest.

With regards to the economic impact of microcredit programs in Malaysia, a few studies had been undertaken to determine the effectiveness of AIM's microcredit program on poverty reduction in Malaysia. The first was an impact assessment study conducted in 1988. The objective of the study is to evaluate the effectiveness of AIM in replicating the Grameen Bank microcredit program in increasing household income of the poor who are involved in the pilot phase of the program. The study is based on a sample size of 283 members. The major finding of the study is that $70 \%$ of AIM members involved in the study experienced significant increase in their monthly household income from an average of RM 142 per month to RM 220 per month (Kasim, 2000). The second internal impact assessment study done by AIM resulted in similar major findings and concluded that access to microcredit facilitates results in an increase in the household income of AIM members (Kasim, 2000).

In the middle of 1990, the SERU of the Malaysia's Prime Minister's Department initiated an impact assessment study on AIM microcredit scheme. The objectives of the study among other things are to evaluate AIM's credit delivery mechanism to their members, AIM's achievement in poverty reduction and the cost-effectiveness of AIM's microcredit scheme in alleviating poverty. SERU had opted to take samples from the state of Kedah, which at the time was an underdeveloped and agriculturalbased state whose population consists of the poor within the rubber and rice sectors. The study found that AIM, using their rigorous means testing, has ensured that only the poor are eligible to get access to their microcredit scheme. In addition, the study also concluded that members' household income has more than doubled from an average of RM 198 before becoming AIM member to RM 457 with access to microcredit scheme. With regards to the cost-effectiveness, the study concluded that with the total operating cost of RM 1,757,019, AIM was able to uplift 249 poor households from the clutches of poverty (Socio-economic Research Unit SERU, 1991). The impact assessment study conducted internally by AIM in 2005 found that AIM microcredit scheme was able to increase client household income from RM 326 before joining the program to RM 932 per month after getting loan from AIM, an increase of $186 \%$ (Amanah Ikhtiar Malaysia AIM, 2008). A recent study by Al-Mamun et al. (2014) attempted to assess the impact of AIM's microcredit program on the level of economic vulnerability among hardcore poor household clients in Peninsular Malaysia using economic vulnerability index. They found that participation in AIM's microcredit program decreases the level of economic vulnerability and it suggested that AIM should emphasize on designing flexible and diversified financial products and delivery methods together with skill development training to improve the socio-economic condition of the hard core poor households in Malaysia.

In summary, most of the previous studies reviewed in this section concentrate on poverty alleviation and the role of women in microfinance in general. Our study mainly investigates the factors affecting per capita income obtained from the scheme by the participants of AIM. 
As oppose to the simple linear regression method, this study uses rigorous statistical tools to examine the impact of microcredit loan, amount of assets, household size, age, duration in the scheme, ratio of spending to income and location on higher and lower household income per capita using a quantile regression method.

\section{Data and methodology}

3.1 Data and variables

Using convenience sampling, we restrict the selection of sample to participants of AIM program in Perak and Kelantan, which have the biggest numbers of participants among all states. In this regard, we apply several stages of stratification. First, two districts in the states of Perak and Kelantan are chosen to represent the members of AIM program. The specific districts chosen are given below:

- Perak - the districts selected are Kuala Kangsar and Teluk Intan.

- Kelantan - the two districts selected are Kota Bharu and Tumpat.

Second, participants are selected randomly from different centers ("pusat”), named by AIM branch offices, in each district. The study is able to collect more than 1,000 responses from the survey. However, only 857 are usable because of missing data in responses. The variables used in the analysis are listed and defined in Table 1.

\subsection{Method of analysis}

To account for the nonlinearity in the relationship between the per capita income after joining AIM and size of loan, size of asset, spending ratio, duration as member of AIM, age, household size and state, the current study relies on the quantile regression framework. The method is adopted because of rationale that the distribution of per capita income of respondents obtained from AIM scheme can be best captured by using several quantiles. The quantile regression, proposed by Koenker and Bassett (1978), can reveal information on the asymmetric and non-linear effects of the conditional variables on the dependent variable. It is applied when an estimate of the various quantiles in a population is desired.

The traditional least squares regression only allows us to approximate the conditional mean and conditional median located at the center of the distribution, which can only give an incomplete description of a conditional distribution (Mosteller and Tukey, 1977). However, quantile regression is used simply to get information about points in the conditional distribution other than the conditional mean (Buchinsky, 1994, 1995; Eide and Showalter, 1997). Other advantages of quantile regression are:

\begin{tabular}{|c|c|c|c|}
\hline Variable & Definition/description & Measurement & \\
\hline nlpcinc & Yearly income per capita after joining AIM & RM (transformed to natural log) & \\
\hline nlloan & Value of loan from microfinance scheme & RM (transformed to natural log) & \\
\hline nlasset & Value of assets possessed & RM (transformed to natural log) & \\
\hline hhsize & Household size/members per house & Units & \\
\hline spdg_inc & Ratio of spending to income from project (monthly) & Percentage & \\
\hline & Age of respondent & Year & \\
\hline dur_aim & Duration being AIM member (months) & Month & Table 1. \\
\hline dumkltn & Dummy Kelantan ( $1=$ Kelantan, $0=$ Perak $)$ & Binary $(1,0)$ & Data and variables \\
\hline
\end{tabular}




\section{EFCC}

1,1

68

- the quantile regression estimator minimizes the weighted sum of absolute residuals rather than the sum of squared residuals, and thus the estimated coefficient vector is not sensitive to outliers;

- a quantile regression model uses a linear programming representation and simplifies examination; and

- it is particularly useful when the conditional distribution does not have a standard shape, such as an asymmetric, fat-tailed or truncated distribution.

The quantile regression approach can thus obtain a much more complete view of the effects of explanatory variables on the dependent variable (Kang and Liu, 2014). This approach is different from the conventional piecewise regressions that segment the dependent variable (unconditional distribution), and then run an ordinary least squares (OLS) on the subsets. Piecewise regressions are not an appropriate alternative to the quantile regression, because of severe sample selection problems (Koenker and Hallock, 2001). Furthermore, piecewise regressions are least-squares based, and can be sensitive to the Gaussian assumption or to the presence of outliers. For more discussion on the model specifications for quantile regression, refer to Koenker (2005).

The basic quantile regression model specifies the conditional quantile as a linear function of explanatory variables. This can be written as follows:

$$
\begin{gathered}
y_{i}=x_{i}^{\prime} \beta_{\theta}+u_{\theta i}, 0<\theta<1 \\
\text { Quant }_{\theta}\left(y_{i} \mid x_{i}\right)=x_{i} \beta_{\theta}
\end{gathered}
$$

where $y$ is the dependent variable, $x$ is a matrix of explanatory variables, $u$ is the error term whose conditional quantile distribution equals zero and Quant $\theta_{\theta}(y i \mid x \mathrm{i})$ denotes the $\theta$ th quantile of $y$ conditional on $x$. The distribution of the error term $u$ is left unspecified. An individual coefficient $\beta_{\theta j}$ associated with the $j$ th independent variable in the vector $x_{i}$, called $x_{i j}$, could be interpreted as "how $y_{i}$ in its $\theta$ th conditional quantile reacts to a (ceteris paribus) marginal change in $x_{i j}$." The quantile regression method allows us to identify the effects of the covariates at different locations in the conditional distribution of the dependent variable.

The $\theta$ th regression quantile estimate, $\hat{\boldsymbol{\beta}}_{\theta}$, is the solution to the following minimization problem:

$$
\min _{\beta} \sum_{y_{i} \geq x_{i}^{\prime} \beta} \theta\left|y_{i}-x_{i}^{\prime} \beta\right|+\sum_{y_{i} \geq x_{i}^{\prime} \beta}(1-\theta)\left|y_{i}-x_{i}^{\prime} \beta\right|,
$$

which is solved via linear programming. The median regression, which is a special case of the quantile regression, is obtained by setting $\theta=0.5$. We can use variations of $\theta$ to obtain other quantiles of the conditional distribution. To convey a sense of the relationships among selected explanatory variables across the conditional per capita income distribution, the results for the 25th, 50th and 75th quantiles are reported. In this study, the bootstrap method is used as illustrated in Buchinsky (1995) to obtain estimates of the standard errors for the coefficients in quantile regression. This analysis is of particular importance as it is a consistent and robust estimation method, especially when the error term is heteroscedastic and non-normally distributed. The following equation is the basic model used in the empirical study: 


$$
\begin{aligned}
\text { nlpcinc }_{i} & =\beta_{0}+\beta_{1} \text { nlasset }_{i}+\beta_{2} \text { nlloan }_{i}+\beta_{3} \text { spdg }_{i} n c_{i}+\beta_{4} \text { dur }_{a} \text { im }_{i}+\beta_{5} \text { age }_{i} \\
& +\beta_{6} \text { hhsize }_{i}+\beta_{7} \text { dummy }_{k} \operatorname{lntn}_{i}+\in
\end{aligned}
$$

Determinants of household income

\section{Results and analysis}

Table 2 shows the descriptive statistics of the variables used in the analysis. As for age of the respondents, the minimum age found is 19 years and the maximum of age is 85 years. The average age among the respondents is 46 years. The minimum household size of respondents is 1 member and the maximum household size is 17 members. On average, the household of respondents is about 5.97 members. The respondents are also asked on the approximate yearly income that they received after joining AIM program. Yearly per capita income is computed by dividing yearly income by household size. The statistics show that the maximum yearly per capita income of respondents is RM 60,000.00 with the mean of RM 4,734.40. As for the ratio of spending to income (after joining AIM), the mean percentage of spending per income is about $55 \%$. The minimum value of loan obtained from AIM scheme among respondents is RM 200.00 and the maximum is RM 22,000.00. Meanwhile, the value of assets belong to respondents, the maximum is RM 420,000.00. Looking at the standard deviation of the data, it is found that there is less variance of data for age, household size and ratio of spending to income because of small number of standard deviation.

Focusing on yearly per capita income, the skewness is 0.3 , which indicates that this dependent variable has skewed distribution. Similarly, the kurtosis statistic is not equal to 3. Thus, the assumption of normal distribution of the error terms in OLS is not guaranteed and it may produce misleading results. Quantile regression can solve these problems as it takes consideration of the conditional distribution which does not have a standard shape.

The empirical analysis is conducted by estimating equation (2) at three quantiles, namely, 25th, 50th and 75th quantiles, using similar list of independent variables for each quantile. It allows us to examine the impact of explanatory variables at different points of income per capita distribution. Table 3 reports the results obtained. For comparison, we also provide the OLS estimates, which are reported at the second column of Table 3. According

\begin{tabular}{|c|c|c|c|c|c|c|c|c|}
\hline Variable & $N$ & Minimum & Maximum & Mean & $\mathrm{SD}$ & Skewness & Kurtosis & \\
\hline Age & 1,742 & 19.00 & 85.00 & 45.66 & 11.40 & 0.271 & -0.191 & \\
\hline Household size & 1,738 & 1.00 & 17.00 & 5.97 & 2.44 & 0.524 & 0.575 & \\
\hline $\begin{array}{l}\text { Yearly per capita } \\
\text { income (RM) } \\
\text { Duration in AIM }\end{array}$ & 1,731 & 0.00 & 60000.00 & 4734.4 & 5102.7 & 0.300 & 0.445 & \\
\hline $\begin{array}{l}\text { (month) } \\
\text { Ratio of spending to }\end{array}$ & 1,743 & 1.00 & 372.00 & 56.8 & 46.8 & 10.211 & 159.059 & Table 2. \\
\hline $\begin{array}{l}\text { Ratio of spending to } \\
\text { income } \\
\text { Value of asset (RM) } \\
\text { Value of loan (RM) }\end{array}$ & $\begin{array}{r}1,718 \\
870 \\
1,741\end{array}$ & $\begin{array}{l}0.00 \\
0 \\
200\end{array}$ & $\begin{array}{r}9.2 \\
420000.00 \\
22000.00\end{array}$ & $\begin{array}{c}0.55 \\
13412.6 \\
3533.86\end{array}$ & $\begin{array}{c}0.53 \\
26758.8 \\
2692.1\end{array}$ & $\begin{array}{l}26.36 \\
-0.717 \\
-0.069\end{array}$ & $\begin{array}{r}783.017 \\
0.194 \\
0.826\end{array}$ & $\begin{array}{r}\text { Descriptive statistics } \\
\text { on continuous } \\
\text { variables }\end{array}$ \\
\hline
\end{tabular}
to the OLS results, only five estimated coefficients are found to be significant at the 
EFCC

1,1

70

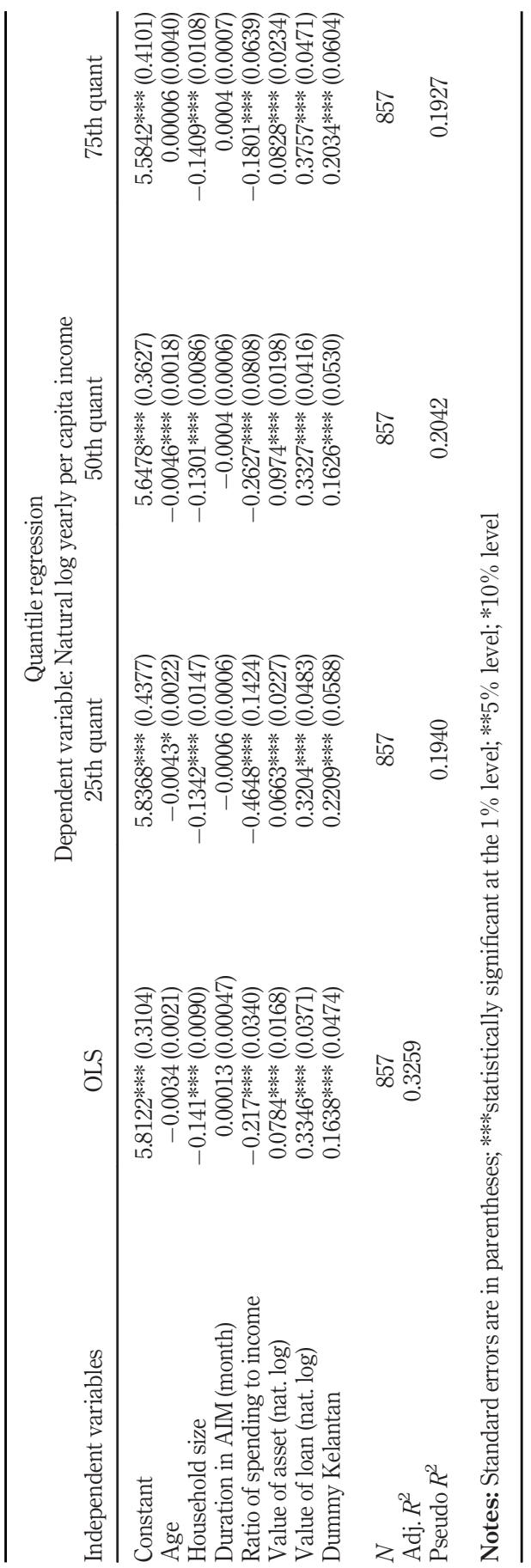

Table 3.

Quantile regression results 

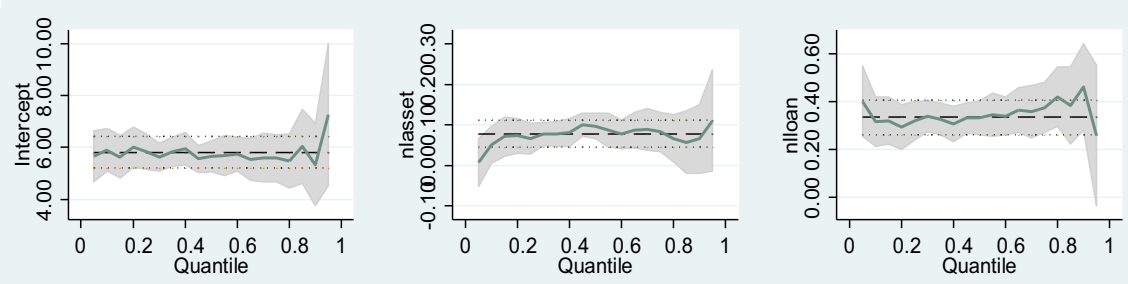

Determinants

of household income
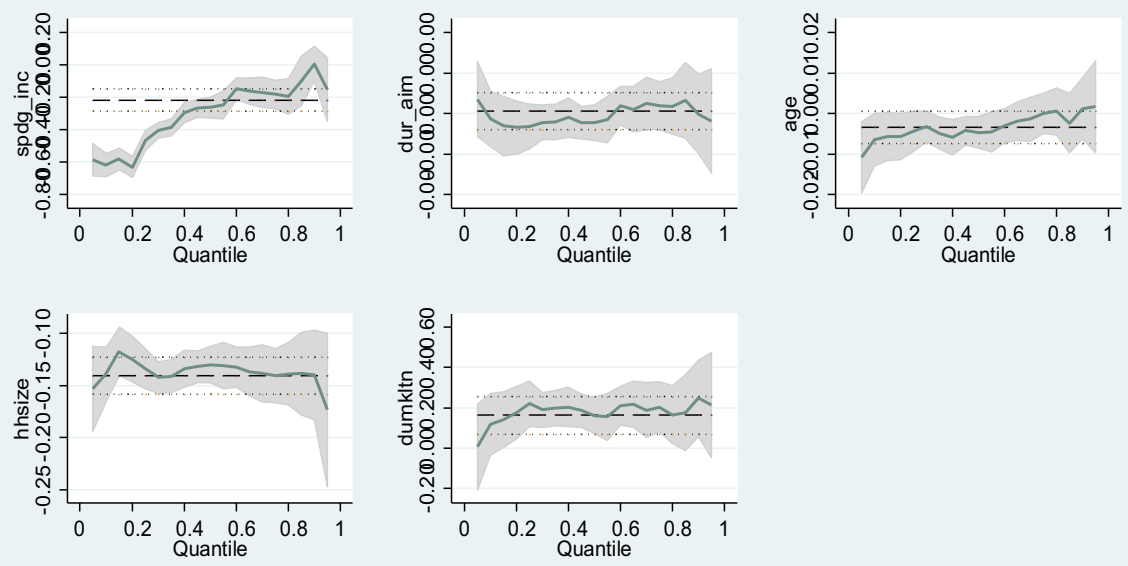

Figure 1.

The trend of coefficients of exploratory variables on dependent variable by quantiles

conventional levels. Those are household size, ratio of spending to income, value of asset, value of loan and dummy variable of state (Kelantan). All variables are significant at $1 \%$ level. Age and duration in AIM scheme do not significantly determine per capita yearly income earned by the participants. Value of asset and value of loan positively contribute to the per capita income but household size and ratio of spending to income contribute negatively contribute to the per capita income of AIM participants. The results indicate that the bigger amount of loan obtained from the scheme as well as the amount of assets possessed, either before or after the involvement in the scheme, are important determinants to higher per capita income obtained currently by participants. However, larger household size and larger spending are contributing lesser per capita income received by the

\begin{tabular}{lcrr}
\hline & & $\tau_{0.25,0.5,0.75}$ & \\
Variable & $F$-statistic & $p$-value & \\
\hline Age & 1.08 & 0.3396 & \\
Household size & 0.60 & 0.5465 & \\
Duration in AIM (month) & 0.92 & 0.3999 & \\
Ratio of spending to income & 2.17 & 0.1148 & Table 4. \\
Value of asset (RM) & 1.09 & 0.3372 & Slope equality test \\
Value of loan (RM) & 0.65 & 0.5229 & results \\
Dummy Kelantan & 0.75 & 0.4719 & \\
\hline
\end{tabular}


EFCC 1,1

respondents. Coefficient of dummy Kelantan is positive and significant which show that those participants in Kelantan are having relatively higher per capita income than those in Perak.

The quantile regression results, though complementing the OLS results, show a different picture. In particular, using quartile regression, age variable which is not significant in OLS regression is now significant at 25th and 50th quantiles. At the 25th quantile of per capita income, age contributes negative and significantly to per capita income at $10 \%$ significance level. The negative relationship is found to be strong and more significant at 50th quantile of per capita income. However, at higher per capita income (75th quantile), age does not significantly affect per capita income. The results indicate that young participants of AIM contribute to higher per capita income when per capita income is at lower and middle levels but it does happen at higher level of per capita income. This suggests that sensitivity of the per capita income obtained from the scheme to the age of participants varies with the location of the quantiles of the per capita income.

Figure 1 shows the pattern of coefficients for each explanatory variable. Our results show evidence of asymmetries. The increasing trend of responsiveness could be seen obviously for coefficients of spending to income ratio, age and value of loan. The figures also show the $90 \%$ confidence intervals, depicted by the shade areas. The pseudo $R^{2}$ statistics are calculated based on Koenker and Machado (1999) and reported for each quantile regression in Table 3. Looking at the value of pseudo $R^{2}$ at each quantile, it could be concluded that per capita incomes are more sensitive to change in most determinants when per capita income is at the middle level as compared to lower or higher levels.

We also report the results of the slope equality tests, proposed by Koenker and Bassett (1978). For each explanatory variable, we test the following hypotheses: $H O: \beta_{0.25}=\beta_{0.50}=$ $\beta_{0.75}$ and $H 1: \beta_{0.25} \neq \beta_{0.50} \neq \beta_{0.75}$ for each coefficient of independent variable. The results are displayed in Table 4 . The results, however, show that the $p$-values of $\mathrm{F}$ statistics for all coefficients are more than 0.05 , which does not reject the null hypothesis. This indicates that the relationship between each independent variable and dependent variables at 25th, 50th and 75th quantiles is not different significantly.

\section{Conclusion}

The present study mainly investigates the factors affecting per capita income obtained from the scheme by the participants of AIM. As oppose to the simple linear regression method, this study uses rigorous statistical tools to examine the impact of microcredit loan, amount of assets, household size, age, duration in the scheme, ratio of spending to income and location on higher and lower household income per capita using a quantile regression method. For this purpose, the study is using data collected from a survey on respondents who are the participants of AIM program using convenience sampling in Perak and Kelantan. The empirical results show that value of asset, value of loan, household size, ratio of spending to income and dummy state are consistently giving similar impacts on per capita income of participants at different quantiles. However, age negatively and significantly affects per capita income only at middle and lower quantiles but not at higher quantile of per capita income. The results indicate that young participants of AIM contribute to higher per capita income when per capita income is at lower and middle levels but not at higher level of per capita income. 


\section{References}

Al-Mamun, A., Mazumder, M.N.H. and Malarvizhi, C.A. (2014), "Measuring the effect of Amanah Ikhtiar Malaysia's microcredit programme on economic vulnerability among hardcore poor households", Progress in Development Studies, Vol. 14 No. 1, pp. 49-59.

Amanah Ikhtiar Malaysia AIM (2008), Annual Report.

Amin, S., Rai, A.S. and Topa, G. (2003), "Does microcredit reach the poor and vulnerable? Evidence from Northern Bangladesh", Journal of Development Economics, Vol. 70 No. 1, pp. 59-82.

Buchinsky, M. (1994), “Changes in U.S. wage structure 1963-1987”, Econometrica, Vol. 62 No. 2, pp. $405-458$.

Buchinsky, M. (1995), "Estimating the asymptotic covariance matrix for quantile regression models: a monte carlo study", Journal of Econometrics, Vol. 68 No. 2, pp. 303-338.

Chowdhury, M.J.A., Ghosh, D. and Wright, R.E. (2005), "The impact of micro-credit on poverty: evidence from Bangladesh", Progress in Development Studies, Vol. 5 No. 4, pp. 298-309.

Coleman, B.E. (2006), "Microfinance in northeast Thailand: who benefits and how much", World Development, Vol. 34 No. 9, pp. 1459-1666.

Conroy, D.J. (2002), "Microfinance in Malaysia: time to rebuilt", available at: www.bwtp.org/ publications/pub/AIM_paper.htm

Della-Giusta, M. and Phillips, C. (2006), "Women entrepreneurs in the Gambia: challenges and opportunities", Journal of International Development, Vol. 18 No. 8, pp. 1051-1064.

Eide, E. and Showalter, M.H. (1997), "Factors affecting the transmission of earnings across generations: a quantile regression approach", The Journal of Human Resources, Vol. 34 No. 2, pp. 253-267.

Hashemi, S.M., Schuler, S.R. and Riley, A.P. (1996), "Rural credit programs and women's empowerment in Bangladesh”, World Development, Vol. 24 No. 4, pp. 635-653.

Kabeer, N. and Noponen, H. (2005), Social Economic Impact of PRADAN's Self Help Group Microfinance and Livelihoods Promotion Program Analysis from Jarkhand, India, The Institute of Development Studies.

Kang, H.H. and Liu, S.B. (2014), "Corporate social responsibility and corporate performance: a quantile regression approach”, Quality and Quantity, Vol. 48 No. 6, pp. 3311-3325.

Kasim, S. (2000), Impact of Banking on Rural Poor in Peninsular Malaysia: Final Report of External Impact Evaluation Study on AIM Active Borrowers, Non-Borrowing Members, Dropouts and Non-Participating Poor, Centre for Policy Research, Universiti Sains Malaysia, Penang.

Koenker, R. (2005), Quantile Regression, Cambridge University Press, New York, NY.

Koenker, R. and Bassett, G. (1978), "Regression quantiles”, Econometrica, Vol. 46 No. 1, pp. 33-50.

Koenker, R. and Hallock, K.F. (2001), "Quantile regression”, Journal of Economic Perspectives, Vol. 15 No. 4, pp. 143-156.

Koenker, R. and Machado, J.A.F. (1999), "Goodness of fit and related inference processes for quantile regression”, Journal of the American Statistical Association, Vol. 94 No. 448, pp. 1296-1310.

McGuire, P.B., Conroy, J.D. and Thapa, G.B. (1998), Getting the Framework Right: policy and Regulation for Microfinance in Asia, The Foundation for Development Cooperatio, Brisbane.

Mayoux, L. (2001), "Tackling the down side: social capital, women's empowerment and micro-finance in Cameroon", Development and Change, Vol. 32 No. 3, pp. 421-450.

Mosteller, F. and Tukey, J.W. (1977), Data Analysis and Regression, Addison-Wesley Publishing, Reading, MA.

Mummidi, T. (2009), "Women and income generating activities: understanding motivations by prioritizing skill, knowledge and capabilities", Working paper 2009-1, French Institute of Pondicherry. 
EFCC

1,1

Park, A. and Ren, C. (2001), "Microfinance with Chinese characterstics", World Development, Vol. 29 No. 1, pp. 39-62.

Pitt, M.M. and Khandker, S.R. (1998), "The impact of group based credit programs on poor households in Bangladesh: does the gender participants matter?", Journal of Political Economy, Vol. 106 No. 5, pp. 958-996.

Rahman, A. (1999), "Micro-credit initiatives for equitable and sustainable development: who pays?", World Development, Vol. 27 No. 1, pp. 67-82.

Socio-economic Research Unit SERU (1991), Impact Evaluation Study of Amanah Ikhtiar Scheme, Prime Minister's Department, Malaysia.

\section{Corresponding author}

Jarita Duasa can be contacted at: jarita@iium.edu.my

For instructions on how to order reprints of this article, please visit our website: 